\title{
Lycopene and resveratrol pretreatment did not interfere with the liver of hepatectomized rats ${ }^{1}$
}

Pedro Paulo Barros', Gisele Mara Silva Gonçalves", Gustavo Henrique da Silva", Maria Clara Villaça Dias Bastos"'I, Loren Nogaroto Ramos"', Marilia Marinello Fernandes ${ }^{\prime \prime \prime}$

'PhD, Full Professor, Researcher, Faculty of Pharmaceutical Sciences, Pontifícia Universidade Católica de Campinas (PUC-Campinas), Brazil. Conception of the study, interpretation of data.

"PhD, Full Professor, Researcher, Faculty of Pharmaceutical Sciences, PUC-Campinas, Brazil. Conception of the study, interpretation of data.

"'Graduate student, School of Medicine, FAPIC, PUC-Campinas, Brazil. Interpretation of data.

\section{Abstract}

Purpose: To investigate the effects of lycopene and resveratrol pretreatment on hepatic hyperplasia in partially hepatectomized rats.

Methods: The lycopene group and the resveratrol group received $40 \mathrm{mg} / \mathrm{kg} / \mathrm{day}$ of lycopene or resveratrol, respectively (dissolved in olive oil or in saline solution, respectively) and administered via a gastric tube for 30 days. The partially hepatectomzed (PH) control groups received saline or olive oil via a gastric tube for 30 days, respectively, and the normal control group received no treatment. Liver tissue and intracardiac blood samples were obtained 24,36 or $48 \mathrm{~h}$ after $\mathrm{PH}$.

Results: No areas of fibrosis were detected. No significant changes in mitotic index, in the number of apoptosis events or in aspartate aminotransferase and alanine aminotransferase levels were observed. Conclusions: Lycopene and resveratrol pretreatment did not interfere on hepatic hyperplasia in partially hepatectomized rats.

Key words: Alanine Transaminase. Aspartate Aminotransferases. Apoptosis. Mitotic Index. Rats. 


\section{- Introduction}

Lycopene, an acyclicform of b-carotene, is present in tomatoes, whose consumption can promote high lycopene concentrations in blood. These concentrations are inversely correlated with the risk for various types of cancers such as prostate cancer ${ }^{1}$, cancer of the digestive apparatus ${ }^{2}$, and pancreatic cancer ${ }^{3}$, also having a protective effect against myocardial infarction ${ }^{4}$. The mechanism by which lycopene can affect carcinogenesis in the prostate is still being investigated. In vitro and animal studies have suggested that the mechanism involved may affect the progression of the cell cycle ${ }^{5}$, the levels of antioxidant enzymes ${ }^{6}$, communication junction ${ }^{7}$, and cell proliferation ${ }^{8}$ in different cancer cell lines.

Lycopene has an antioxidant action ${ }^{9}$ and its daily ingestion can strengthen the antioxidant system and inhibit lipid peroxidation in humans $\mathrm{s}^{10}$.

Various lycopene doses have been studied. For example, patients with cancer of the prostate treated orally with lycopene capsules (30 mg/day/3 weeks) showed a reduction of tumor size and of plasma PSA levels compared to control $^{11}$. Oral doses of 10 ou $50 \mathrm{mg} / \mathrm{kg} / 2$ weeks inhibited lipid peroxidation of hepatic tissue in rats $^{12}$. Bahcecioglu et al. ${ }^{13}$ observed that lycopene $(2 \mathrm{mg} / \mathrm{kg}$ ) had a preventive effect against the development of non-alcoholic steatohepatitis induced by a high lipid diet, attributed to its antioxidant action. Bestas et al. ${ }^{14}$, in a study of the preventive action of lycopene $(25 \mathrm{mg} /$ $\mathrm{kg} /$ day) and of vitamin E (100 IU/ $/ \mathrm{kg} /$ day $)$ against halothane-induced hepatotoxicity, observed that only lycopene had a significant hepatoprotective activity.

Resveratrol (3,5,4 trihydroxystilbene) is a natural polyphenol detected in many plant species, including the grape vine (Vitis vinifera). Resveratrol occurs in two forms, i.e., cis and trans, with the trans form being biologically more active. The benefits of resveratrol consumption have stimulated various investigations of this substance. Over the last few decades, resveratrol has attracted the attention of scientists all over the world because of its anticancer, anti-inflammatory, and hypoglycemic activities, in addition to other cardiovascular benefits. In order to confirm these properties, resveratrol has been studied in experimental mouse and rat models ${ }^{15}$. It was first observed that resveratrol prolongs the life of lower organisms, simulating the anti-aging effects of calorie restriction ${ }^{16}$. Resveratrol has a vasoprotective action in animal models of diabetes mellitus, improving endothelial function and attenuating vascular inflammation ${ }^{17,18}$. In addition, the Mediterranean diet, rich in resveratrol, is associated with a reduced risk of cardiovascular mortality in human beings ${ }^{19}$.

Resveratrol is a neutralizer of free radicals ${ }^{20}$. The antioxidant capacity of polyphenol compounds depends on the redox properties of their phenolic hydroxyl groups and on the potential of electron dislocation throughout their chemical structure ${ }^{21}$. The common recognition of resveratrol as a natural antioxidant was explicitly reported by Zini et al. ${ }^{22}$. Resveratrol has three different antioxidant mechanisms: (a) competition with coenzyme $Q$ to reduce the oxidative chain complex, the site of production of reactive oxygen species (ROS), (ii) neutralization of O2- radicals formed in the mitochondria, and (iii) inhibition of lipid peroxidation induced by Fenton reaction products.

Resveratrol, as a natural antioxidant, can neutralize some intracellular ROS. Although it is not a potent antioxidant in vitro, resveratrol has a high antioxidant activity in vivo, probably due to its ability to increase the synthesis of nitric oxide, which in turn acts as 
an antioxidant ${ }^{15}$.

Resveratrol has been studied in order to confirm its hepatoprotective actionsin addition to its various actions already described. Lee et al. ${ }^{23}$ reported that resveratrol $(20 \mathrm{mg} / \mathrm{kg}$ daily for 4 weeks) showed in vivo hepatoprotective and antifibrinogenic activity on hepatic injury induced by dimethylnitrosoamine by inhibiting the elevation of serum transaminases, suggesting its possible usefulness in the prevention of the development of hepatic fibrosis. Tunali-Tunali et al. ${ }^{24}$ obtained similar results with an oral resveratrol dose of $10 \mathrm{mg} /$ $\mathrm{kg}$ applied to rats with methotrexate-induced liver injury, which could be a therapeutic option for minimizing the systemic side effects of chemotherapeutic agents. Gedik et al. ${ }^{25}$ reported that resveratrol $(10 \mathrm{mg} / \mathrm{kg})$ had hepatoprotective activity in rats submitted to ischemia and reperfusion, an effect possibly associated with its antioxidant activity against the free radicals released during the period of reperfusion. Das et al. ${ }^{26}$ demonstrated that resveratrol at the dose of $5 \mathrm{mg} / \mathrm{kg} /$ day showed immunomodulatory activity and effectively improved the angiogenesis process and the oxidative changes induced by ethanol in mice.

The aim of the present study was to investigate the effects of lycopene and resveratrol pretreatment on hyperplasia of the liver in partially hepatectomized rats.

\section{Methods}

The study protocol was approved by the Animal Research Ethics Committee Pontiifícia Universidade Católica de Campinas (Protocol 033/2013) according to the Guide for the Care and Use of Laboratory Animals.

\section{Materials}

Reagents were acquired from the following sources: resveratrol and lycopene
(All Chemistry do BrasilTM), vincristine sulfate (Libbs FarmaceuticaTM); enzyme assay kit (LaborLab). All other reagents were analytical grade.

\section{Animals}

Forty-five-day-old male Wistar rats (Rattus norgevicus, non-isogenic) ( $n=65)$, weighing $200 \pm 10 \mathrm{~g}$ were obtained from the Animal Facility of the Life Sciences Center (Pontifícal Catholic University of Campinas, SP, Brazil). Throughout the experiments, the animals were maintained in rooms with controlled temperature $\left(23 \pm 1^{\circ} \mathrm{C}\right)$ under a 12-hour light/dark cycle, with free access to commercial chow (Nuvilab) and water.

\section{Partial hepatectomy}

Animals were divided into a Normal control group (NC), a Lycopene group (LPH) and its Partial Hepatectomy Control group (PH1), a Resveratrol group (RPH) and its Partial Hepatectomy Control group (PH2) (Figure 1). Except for NC, the remaining groups were further divided into three subgroups $(n=5$ in each subgroup). LPH animals received $40 \mathrm{mg} /$ $\mathrm{kg} /$ day lycopene dissolved in olive oil for a volume of $1 \mathrm{~mL}$ and administered via a gastric tube for 30 days. RPH animals received 40 $\mathrm{mg} / \mathrm{kg} /$ day resveratrol in saline solution for a volume of $1 \mathrm{~mL}$ administered via a gastric tube for 30 days. The two $\mathrm{PH}$ control groups of the groups treated with lycopene and resveratrol respectively received $1 \mathrm{~mL}$ olive oil or saline solution administered via a gastric tube for 30 days. Next, the rats underwent partial hepatectomy and, after 24,36 or $48 \mathrm{~h}$, they received an intraperitoneal injection of vincristine sulfate $(1 \mathrm{mg} / \mathrm{kg})$. Rats were injected with vincristine to block the cell cycle of all hepatocytes at the M phase ${ }^{27}$. NC animals were only kept under the same housing conditions with no treatment or surgical procedures and 
only received the vincristine sulfate injection like the other groups. After $2 \mathrm{~h}$, the animals were anesthetized for removal of liver tissue. Three $\mathrm{ml}$ intracardiac blood samples were drawn for biochemical anal-ysis, followed by euthanasia with ketamine and xylazine.

$\mathrm{PH}$ was carried out as described by Higgins and Anderson ${ }^{28}$. This procedure involves the surgical removal of about $70 \%$ of liver tissue. Samples of the remaining lobes were obtained 24,36 or $48 \mathrm{~h}$ after surgery and used for histological and histochemical analyses.

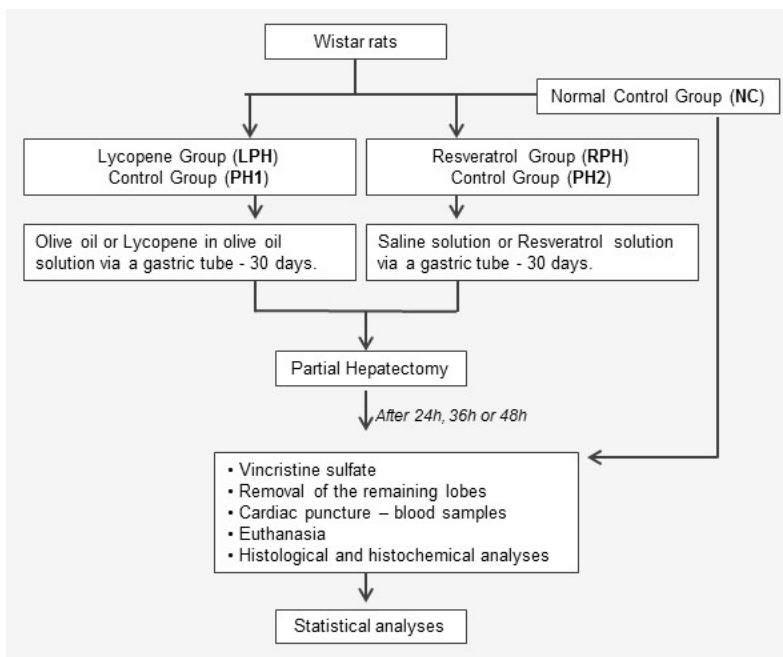

Figure 1 - Experimental design.

\section{Histological processing}

Liver tissue fragments were cut into 7 $\mu \mathrm{m}$-thick slices and stained with hematoxylineosin (HE) and by the Feulgen method (FM). The FM allows to clearly visualize the hepatocyte nucleus and to identify the mitosis. Masson's trichrome staining was not performed since the presence of fibrosis identifiable by microscopy was not expected within the short period of the experiment. Images were captured digitally using a photomicroscope (Nikon Eclipse E200 ${ }^{\mathrm{TM}}$ ) coupled to a camera (Nikon Colpix $4500^{\mathrm{TM}}$ ). Mitotic index and apoptosis were assessed after $\mathrm{PH}$.

\section{Determination of enzyme activity}

ALT and AST activity was determined in blood serum using LaborLab ${ }^{\mathrm{TM}}$ kits and a UV-Vis Varian ${ }^{\mathrm{TM}}$ spectrophotometer.

\section{Data analysis}

Data a re reported as number of findings per micrograph. Mitotic and apoptotic figures were counted in 20 fields per liver tissue section stained with HE and FM. Statistical analysis of morphometry, AST and ALT data was performed using Graph Pad PRISMTM 3.0 software. The Kruskal-Wallis test and Dunn's post-test $(p<0.05)$ were used for group comparisons. The " $n$ " used was statistically determined in order to obtain reliable results.

\section{Results}

As expected, histological analysis of the Normal control group revealed a reduced number of mitosis and apoptosis. During the experimental period, no histologic alterations were detected in the liver of the remaining groups studied, indicating the absence of hepatic injury due to the treatments/ procedures performed.

The analysis of mitotic index and of the number of apoptosis events (Tables 1 and 2 , Figure 1) showed that the administration of lycopene or resveratrol before $\mathrm{PH}$ did not interfere with these parameters. Comparison of the mitotic and apoptotic indices of the control PH group to those of the lycopene and resveratrol groups revealed no significant difference, probably indicating that, under the experimental conditions of the present study, the two substances did not interfere with the processes of hepatic hyperplasia. Regarding 
transaminase levels, the normal control group showed values of $15.41 \pm 4.71 \mathrm{U} / \mathrm{L}$ for AST and $58.72 \pm 27.22 \mathrm{U} / \mathrm{L}$ for ALT, statistically different values from those observed in the remaining groups $(p<0.05)$, confirming the structural injury due to $\mathrm{PH}$ (Figures 2 and 3 ).

Table 1 - Mitotic index and apoptosis index for Partial Hepatectomy (PH2) and Resveratrol+Partial Hepatectomy hepatic tissues (RPH).

\begin{tabular}{lccccc}
\hline \multicolumn{5}{c}{ Mitotic index } \\
\hline PH24 & RPH24 & PH36 & RPH36 & PH48 & RPH48 \\
\hline $39.44 \pm 7.4$ & $26.78 \pm 7.1$ & $30.25 \pm 4.6$ & $19.82 \pm 2.9$ & $21.85 \pm 3.4$ & $15.79 \pm 5.0$ \\
\hline PH24 & Apoptotic index & & \\
\hline $0.36 \pm 0.3$ & RPH24 & PH36 & RPH36 & PH48 & RPH48 \\
\hline
\end{tabular}

PH24, PH36 and PH48: Groups examined 24, 36 and 48 h after partial hepatectomy, respectively; RPH24, RPH36 and RPH48: Resveratrol-treated groups examined 24, 36 and $48 \mathrm{~h}$ after partial hepatetomy, respectively. The Kruskal-Wallis Test and Dunn's posttest showed no significant difference when each group was compared to its respective control.

Table 2 - Mitotic index and apoptosis index for Partial Hepatectomy (PH1), and Lycopene + Partial Hepatectomy hepatic tissues (LPH).

\begin{tabular}{lccccc}
\hline \multicolumn{7}{c}{ Mitotic index } \\
\hline PH24 & LPH24 & PH36 & LPH36 & PH48 & LPH48 \\
\hline $14.67 \pm 9.7$ & $23.45 \pm 5.5$ & $7.34 \pm 1.3$ & $12.44 \pm 6.4$ & $10.46 \pm 2.0$ & $9.22 \pm 3.5$ \\
\hline \multicolumn{5}{c}{ Apoptosis Index } \\
\hline PH24 & LPH24 & PH36 & LPH36 & PH48 & LPH48 \\
\hline $0.49 \pm 0.4$ & $0.36 \pm 0.7$ & $1.01 \pm 0.9$ & $1.80 \pm 1.4$ & $5.93 \pm 5.1$ & $8.64 \pm 6.4$
\end{tabular}

PH24, PH36 and PH48: Groups examined 24, 36 and $48 \mathrm{~h}$ after partial hepatectomy, respectively; LPH24, LPH36 and LPH48: Lycopenetreated groups examined 24, 36 and 48h after partial hepatetomy, respectively. The Kruskal-Wallis Test and Dunn's post-test showed no significant difference when each group was compared to its respective control. 


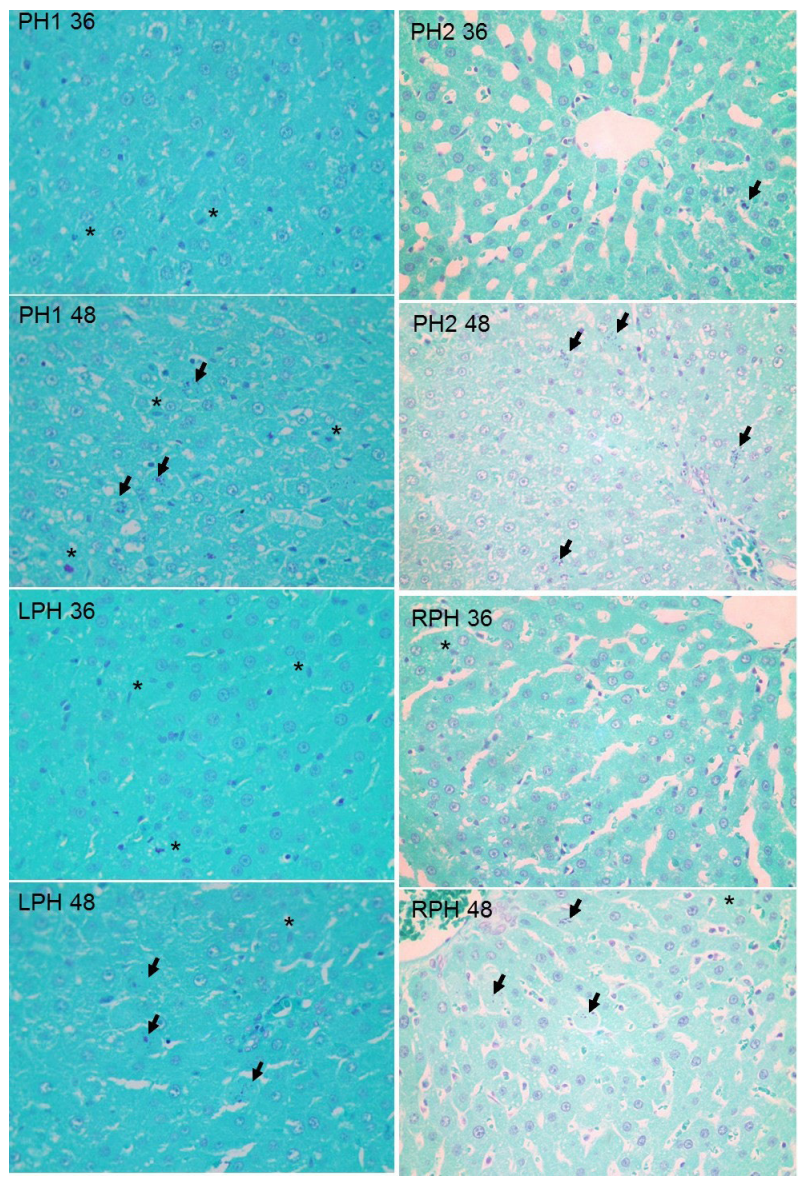

Figure 2 - Liver, Hepatocyte - Mitosis (asterisks) and Apoptosis (arrows) in Wistar rats. Control groups after 36 and 48 hours of partial hepatectomy (PH1 36, PH1 48, $\mathrm{PH} 236$ and $\mathrm{PH} 48$, respectively). Lycopene or resveratrol groups, after 36 and 48 hours of partial hepatectomy (LPH 36, LPH 48, RPH 36 and RPH 48, respectively. Feulgen stain, $\mathrm{x} 400$.

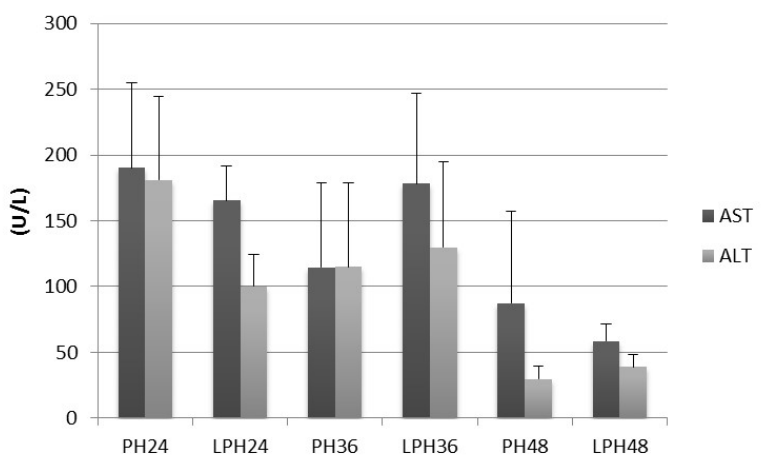

Figure 3 - Clinical parameters of rats submitted to Partial Hepatectomy, and Lycopene + Partial Hepatectomy. AST=Aspartate aminotransferase; $\quad A L T=A l a n i n e$ aminotransferase. PH24, PH36 and PH48: Groups examined 24, 36 and $48 \mathrm{~h}$ after partial hepatectomy, respectively; LPH24, LPH36 and LPH48: Lycopenetreated groups examined at 24, 36 and $48 \mathrm{~h}$, respectively. The Kruskal-Wallis test and Dunn's post-test showed no significant difference when each group was compared to its respective control. AST =15.4. 4.71 and ALT $=58.72 \pm 27.2$ for the Normal Control Group.

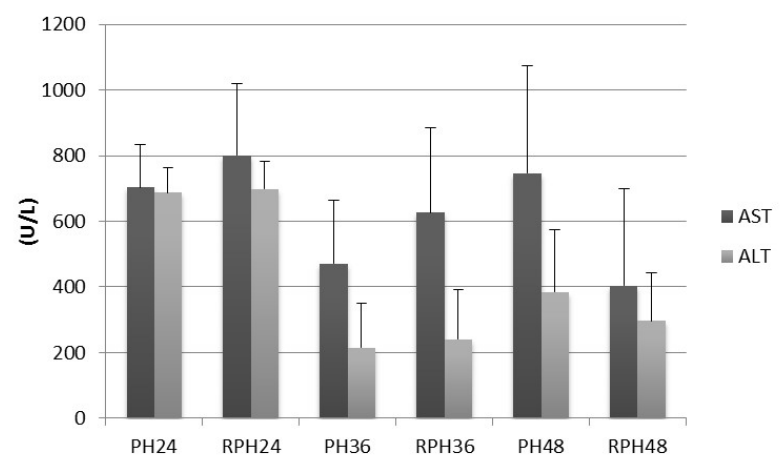

Figure 4 - Clinical parameters of rats submitted to Partial Hepatectomy, and Resveratrol + Partial Hepatectomy rats. AST=Aspartate aminotransferase; $A L T=A l a n i n e$ aminotransferase. PH24, PH36 and PH48: Partial hepatectomy groups 24, 36 and 48 hours, respectively; RPH24, RPH36 and RPH48: Resveratrol treated groupS 24, 36 and 48 hours, respectively. The Kruskal-Wallis test and Dunn's post-test showed no significant difference when each group was compared to its respective control. AST $=15.4 . \pm 4.71$ and $A L T=58.72 \pm 27.2$ for the Normal Control Group.

\section{- Discussion}

Advances in molecular techniques over the past few decades have resulted in the development of regenerative medicine methods. Thus, liver regeneration and $\mathrm{PH}$ rat models have been used extensively to explore regeneration mechanisms, liver disease pathogenesis, and drug screening ${ }^{29}$.

In this study, the absence of statistically significant results in the mitotic index and apoptosis events in the experimental groups suggests that both lycopene and resveratrol, previously administered to $\mathrm{PH}$, did not interfere with hepatic hyperplasia and the experimental 
$\mathrm{PH}$ is a surgical procedure leading to a tissue injury that can be verified by increasing serum transaminase levels. In our study, these levels were lower in the normal control group, which was expected.

Regarding transaminase levels, the normal control group showed values of 15.41 $\pm 4.71 \mathrm{U} / \mathrm{L}$ for AST and $58.72 \pm 27.22 \mathrm{U} / \mathrm{L}$ for $A L T$, statistically different values from those observed in the remaining groups $(p<0.05)$, confirming the structural injury due to $\mathrm{PH}$.

Similarly, comparison of the results presented in Figures 2 and 3 showed that AST and ALT levels did not differ in the lycopene or resveratrol groups in relation to their respective controls. These data are different from those reported by Aidoud et al. ${ }^{30}$ who observed a significant reduction of serum ALT, AST and alkaline phosphatase in a study on Wistar rats fed a lycopene-rich diet in combination with olive oil for four weeks. These authors concluded that such diet contributed to the amelioration of liver fuction disorders by modulating the hepatic enzyme levels and enhancing the antioxidant level of liver tissue.

Although in the present study resveratrol did not induce statistically significant changes in transaminase levels, this result does not indicate that resveratrol is inefficient for hepatoprotection. According to Walle et al. ${ }^{31}$ : "in general, the doses of resveratrol have been higher in animals than in humans". Kirimlioglu et al. ${ }^{32}$ investigated the antioxidant status of rats after resveratrol treatment following $70 \%$ partial hepatectomy and reported that the group treated with $60 \mathrm{mg} /$ day resveratrol 7 days before and 3 days after $\mathrm{PH}$ showed reduced glutathione and malondialdehyde levels, as well as reduced NO and interleukin- 6 levels. These authors also concluded that resveratrol seemed to reduce the traumatic effects of $\mathrm{PH}$ and might be useful in donors and recipients undergoing living donor liver transplantation.

Various substances of plant origin have been studied in order to determine their proliferative action on hepatic tissue. Toydemir et al. ${ }^{33}$ detected the antioxidative, antiapoptotic, and proliferative effect of curcumin on liver regeneration after partial hepatectomy in rats and concuded that curcumin had a beneficial effect on the regenerative capacity of remnant liver tissue. Yang et al. ${ }^{29}$ explored the effect of fructus polygoni orientalis extract (EFPO) on liver regeneration and the proliferation of bone marrow cells in a rat model of partial hepatectomy and concluded that EFPO inhibited liver regeneration and liver repair after $\mathrm{PH}$ in rats. Lima et al. ${ }^{34}$ assessed the effects of an aqueous extract of Hyptis fructicosa leaves on liver regeneration after $67 \%$ partial hepatectomy in rats and observed that, at the dose of $100 \mathrm{mg} / \mathrm{kg} /$ day, this extract can stimulate hepatic regeneration. These studies motivated the present investigation with licopene and resveratrol, which, in the present model, did not seem to interfere with the proliferative process of hepatocytes, also showing no antiapoptotic activity. According to Toydemir et al. ${ }^{33}$, the role for apoptosis in theliver after hepatectomy seems to be controversial. At the peak of regeneration, apoptosis begins. Accompanying cell reproduction, cell apoptosis would eliminate the overgrown cells, and rebuilding of the constitution is achieved.

The absence of a proliferative and antiapoptotic activity observed for resveratrol appears to be compatible with its antioxidant capacity ${ }^{15}$. The latter is effective in organic disorders provoked by free radicals, something that does not occur significantly in PH. Licopene, in turn, has antiproliferative activity against cancer cells $s^{8}$, however, the metabolism of these cells is known to be quite different from that of "normal" cells, a fact that may justify the absence of proliferative (or antiproliferative) activity of licopene in the present study.

\section{- Conclusion}

The absence of changes in transaminase levels does not mean that treatment with lycopene or resveratrol may not be useful as 
a preoperative measure in hepatic surgeries. It may be suggested that these substances probably do not interfere with the human liver, but are suitable for other therapeutic purposes.

\section{References}

1. Giovannucci E. Tomatoes, tomato-based products, lycopene, and cancer: review of the epidemiologic literature. J Natl Cancer Inst. 1999;91:317-31. PMID: 10050865.

2. Franceschi S, Bidoli E, La Vecchia C, Talamini R, D'avanzo B, Negri E. Tomatoes and risk of digestive-tract cancers. Int J Cancer. 1994;59:181-4. PMID: 7927916.

3. Burney PG, Comstock GW, Morris JS. Serologic precursors of cancer: serum micronutrients and the subsequent risk of pancreatic cancer. Am J Clin Nutr. 1989;49:895-900. PMID: 2718925.

4. Kohlmeier L, Kark JD, Gomez-Gracia E, Martin BC, Steck SE, Kardinaal AF, Ringstad J, Thamm M, Masaev V, Riemersma R, Martin-Moreno JM, Huttunen JK, Kok FJ. Lycopene and myocardial infarction risk in the EURAMIC Study. Am J Epidemiol. 1997;146:618-26. PMID: 9345115.

5. Karas $M$, Amir $H$, Fishman $D$, Danilenko $M$, Segal S, Nahum A, Koifmann A, Giat y, Levy j, sharoni y. Lycopene interferes with cell cycle progression and insulin-like growth factor I signaling in mammary cancer cells. Nutr Cancer. 2000;36:101-11. PMID: 10798222.

6. Breinholt V, Lauridsen ST, Daneshvar B, Jakobsen J. Dose-response effects of lycopene on selected drug-metabolizing and antioxidant enzymes in the rat. Cancer Lett. 2000;154:201-10. PMID: 10806309.

7. Stahl W, Von Laar J, Martin HD, Emmerich $T$, Sies $H$. Stimulation of gap junctional communication: comparison of acycloretinoic acid and lycopene. Arch Biochem Biophys. 2000;373:271-4. PMID: 10620348.

8. Levy J, Bosin E, Feldman B, Giat Y, Miinster A, Danilenko $M$, Sharoni $Y$. Lycopene is a more potent inhibitor of human cancer cell proliferation than either -carotene or -carotene. Nutr Cancer. 1995;24:257-66. doi: $10.1080 / 01635589509514415$.

9. Shami NJI, Moreira EAM. Lycopene como agenteantioxidante. Rev Nutr. 2004;17(2):22736. doi: 10.1590/S1415-52732004000200009.
10. Visioli F, Riso P, Grande S, Galli C, Porrini M. Protective activity of tomato products on in vivo markers of lipid oxidation. Eur J Nutr. 2003;42(4):201-6. PMID: 12923651.

11. Kucuk O, Sarkar FH, Sakr W, Djuric Z, Pollak MN, Khachik F, Li YW, Banerjee M, Grignon D, Bertram JS, Crissman JD, Pontes EJ, Wood DP Jr. Phase II Randomized clinical trial of lycopene supplementation before radical prostactectomy. Cancer Epidemiol Biomarkers Prev. 2001;10:861-8. PMID: 11489752.

12. Kravchenko LV, Morozov SV, Beketova NA, Deryagina VP, Avren'eva LI, TUTEL'YAN, VA. Antioxidant status of rats receiving lycopene in different doses. Bull Exp Biol Med. 2003;135(4):353-7. PMID: 12910307.

13. Bahcecioglu IH, Kuzu N, Metin K, Ozercan $\mathrm{IH}$, Ustündag B, Sahin K, Kucuk O. Lycopene prevents development of steatohepatitis in experimental nonalcoholic steatohepatitis model induced by high-fat diet. Vet Med Int. 2010;2010. PMID: 20953409.

14. Bestas A, Kahramanoglu M, Erhan OL, Bolat E, Ozercan I, Gürsu F, Gülcü F. The role of the antioxidants lycopene and vitamin $E$ in the prevention of halothane induced hepatotoxicity. Methods Find Exp Clin Pharmacol. 2008;30(8):627-31. PMID: 19088947.

15. Mukherjee S, Dudley JI, Das DK. Dosedependency of resveratrol in providing health benefits. Dose-Response. 2010;8:478-500. PMID: 21191486.

16. Wood JG, Rogina B, Lavu S, Howitz K, Helfand SL, Tatar M, Sinclair D. Sirtuin activators mimic caloric restriction and delay ageing in metazoans. Nature. 2004;430:686-9. doi: 10.1038 /nature02789.

17. Sharma S, Anjaneyulu M, Kulkarni SK, Chopra K. Resveratrol, a polyphenolic phytoalexin, attenuates diabetic nephropathy in rats. Pharmacology. 2006;76:69-75. PMID: 16286809.

18. Su HC, Hung LM, Chen JK. Resveratrol, a red wine antioxidant, possesses an insulinlike effect in streptozotocin-induced diabetic rats. Am J Physiol Endocrinol Metab. 2006;290:E1339-46. PMID: 16434553.

19. Keys A, Menotti A, Karvonen MJ, Aravanis C, Blackburn H, Buzina R, Djordjevic BS, Dontas AS, Fidanza F, Keys MH, Kromhout D, Nedeljkovic S, Punsar S, Seccareccia F, Toshima $\mathrm{H}$. The diet and 15 -year death rate 
in the seven countries study. Am J Epidemiol. 1986;124:903-15. PMID: 3776973.

20. Gusman J, Malonne H, Atassi G. A reappraisal of the potential chemopreventive and chemotherapeutic properties of resveratrol. Carcinogenesis. 2001;22:1111-7. PMID: 11470738.

21. Jang M Pezzuto JM. Cancer chemopreventive activity of resveratrol. Drug Exp Clin Res. 1999;25:65-77. PMID: 8985016.

22. Zini R, Morin C, Bertelli A, Bertelli AA, Tillement JP. Effects of resveratrol on the rat brain respiratory chain. Drugs Exp Clin Res. 1999;25:87-97. PMID: 10370869.

23. Lee Es, Shin Mo, Yoon S, Moon JO.Resveratrol inhibits dimethylnitrosamine-induced hepatic fibrosis in rats. Arch Pharm Res. 2010;33(6):925-32. PMID: 20607498.

24. Tunali-Akbay T, Sehirli O, Ercan F, Sener G. Resveratrol protects against methotrexateinduced hepatic injury in rats. J Pharm Pharmaceut Sci. 2010;13(2):303-10. PMID: 20816014.

25. Gedik E, Girgin S, Ozturk H, Obay BD, Ozturk $\mathrm{H}$, Buyukbayram $\mathrm{H}$. Resveratrol attenuates oxidative stress and histological alterations induced by liver ischemia/reperfusion in rats. World J Gastroenterol. 2008;14(46):7101-6. doi: 10.3748/wjg.14.7101.

26. Das SK, Mukherjee S, Gupta G, Rao DN, Vasudevan DM. Protective effect of resveratrol and vitamin $E$ against ethanol-induced oxidative damage in mice: biochemical and immunological basis. Indian J Biochem Biophys. 2010;47(1):32-7. PMID: 21086752.

27. Tomizawa M, Miyamoto T, Kato H, Otsu H. Relative biological effectiveness of carbon ions for causing fatal liver failure after partial hepatectomy in mice. J Radiat Res.
2000;41:151-61. doi: 10.1269/jrr.41.151.

28. Higgins, GM, Anderson RM. Experimental pathology of the liver: I. Restoration of the liver of the white rat following partial surgical removal. Arch Pathol. 1931;12:186-202.

29. Yang JY,Wang JS, Liu HB. Fructus polygoni orentalis extract inhibited liver regeneration and proliferation of bone marrow cells of rat after partial hepatectomy. Genet Mol Res. 2015;14(3):7671-9. doi: 10.4238/2015. July.13.12.

30. Aidoud A, Elahcene O, Ammouche A, Rodriguez AB. Hepatoprotective effect of olive and argan oils supplemented with tomato lycopene in wistar rats. Pak J Nutr. 2016;15(4):347-51. doi: 10.3923/pjn.2016.347.351.

31. Walle T, Hsieh F, DeLegge $\mathrm{MH}$, Oatis JE, Walle UK. High absorption but very low bioavailability of oral Resveratrol in humans. Drug Metab Dispos. 2004;32(12):1377-82. doi: $10.1124 /$ dmd.104.000885.

32. Kirimlioglu V, Karakayali H, Turkoglu S, Haberal $M$. Effect of resveratrol on oxidative stress enzymes in rats subjected to $70 \%$ partial hepatectomy. Transplant Proc. 2008;40:2936. PMID: 18261609.

33. Toydemir T, Kanter M, Erboga M, Oguz S, Erenoglu C. Antioxidative, antiapoptotic, and proliferative effect of curcumin on liver re generation after partial hepatectomy in rats. Toxicol Industrial Health. 2015;31(2):162-72. doi: $10.1177 / 0748233712469658$.

34. Lima SO, Viana LC, Santana FRT, Zucoloto $\mathrm{S}$, Albuquerque Junior $\mathrm{RL}$, Gomes $\mathrm{MZ}$. Proliferative effect of aqueous extract of Hyptis fructicosa on liver regeneration after partial hepatectomy in rats1. Acta Cir Bras. 2012;27(1):71-5. doi: 10.1590/S010286502012000100012.

\section{Correspondence:}

Pedro Paulo Barros

Faculdade de Ciências Farmacêuticas

Avenida John Boyd Dunlop, s/n

13060-904 Campinas - SP Brasil

Tel.: (55 19)3343-6865

barrospp@puc-campinas.edu.br

Received: Nov 19, 2016

Review: Jan 17, 2017

Accepted: Feb 21, 2017
Conflict of interest: none

Financial source: none

\begin{abstract}
${ }^{1}$ Research performed at Laboratory of Biological Tests, Faculty of Nutrition, Pontificia Universidade Católica de Campinas (PUCCampinas), Brazil.
\end{abstract}

